\title{
Zeolite Encapsulated Nanocrystalline CuO: A Redox Catalyst for the Oxidation of Secondary Alcohols
}

\author{
Sakthivel Vijaikumar, Thirumeni Subramanian, and Kasi Pitchumani \\ School of Chemistry, Madurai Kamaraj University, Madurai 625-021, India
}

Correspondence should be addressed to Kasi Pitchumani, pit12399@yahoo.com

Received 21 September 2007; Revised 4 February 2008; Accepted 24 March 2008

Recommended by N. Xu

Zeolite encapsulated nanocrystalline $\mathrm{CuO}$ is synthesized and characterized by powder XRD and HRTEM analyses which clearly show that the particles are less than $15 \mathrm{~nm}$ and the nanoparticles are highly dispersed. This nano CuO encapsulated CuY zeolite is used as catalyst in the oxidation of aromatic secondary alcohols. CuY zeolite acts as an efficient support for nano CuO, by stabilizing it and preventing its aggregation. Plausible mechanisms for the formation of the various products are also given.

Copyright ( $) 2008$ Sakthivel Vijaikumar et al. This is an open access article distributed under the Creative Commons Attribution License, which permits unrestricted use, distribution, and reproduction in any medium, provided the original work is properly cited.

\section{INTRODUCTION}

Nanostructured materials present great promise and opportunities for a new generation of materials with improved and tailorable properties for applications in sensors, optoelectronics, separation, and catalysis. Catalysts in many cases are nanoscale particles, and thus catalysis is a nanoscale phenomenon [1,2]. Significant progress has been made in recent years in controlling the size of nanoscale materials and in understanding their unique size-dependent catalytic properties [3]. In this context, controlling the shape of nanoparticles is also an equally important aspect of desired catalyst synthesis [4]. Nanostructured materials, especially nanometal oxides such as $\mathrm{MgO}, \mathrm{CuO}, \mathrm{Al}_{2} \mathrm{O}_{3}, \mathrm{CaO}, \mathrm{BaO}$, $\mathrm{SrO}, \mathrm{ZnO}$, and $\mathrm{TiO}_{2}$, exhibit great promise and opportunities for a new generation of materials with improved and tailorable properties for applications in sensor development, optoelectronics, separation, and catalysis studies [5]. Among these nanometal oxides, $\mathrm{CuO}$ has gained advantages because of its higher catalytic activity in many oxidation processes [6].

Various preparation methods to ultrafine $\mathrm{CuO}$ have been reported [7-10]. Bandara et al. [11] have reported the synthesis of highly stable $\mathrm{CuO}$ incorporated $\mathrm{TiO}_{2}$ and these catalysts have higher catalytic activity in the photocatalytic reduction of $\mathrm{H}_{2} \mathrm{O}$ under sacrificial conditions. Liquid-phase oxidation of benzene to phenol catalyzed by $\mathrm{CuO}$ supported $\mathrm{Al}_{2} \mathrm{O}_{3}$ has been reported by Miyahara et al. [12]. They have also reported that $\mathrm{CuO}$ supported $\mathrm{Al}_{2} \mathrm{O}_{3}$ prepared by coprecipitation of $\mathrm{Cu}\left(\mathrm{NO}_{3}\right)_{2} \cdot \mathrm{H}_{2} \mathrm{O}$ and $\mathrm{Al}\left(\mathrm{NO}_{3}\right)_{3} \cdot 9 \mathrm{H}_{2} \mathrm{O}$ inhibits the leaching of $\mathrm{Cu}$ species in comparison with the $\mathrm{Cu}$ catalysts supported by the impregnation method on $\mathrm{Al}_{2} \mathrm{O}_{3}, \mathrm{SiO}_{2}, \mathrm{MCM}-41$, and so forth. Mixed oxides of $\mathrm{Cu}-\mathrm{Mn}$ derived from calcination of $\mathrm{Cu}-\mathrm{Mn}$-hydrotalcite precursors are reported to be promising catalysts for the total combustion of toluene [13].

Oxidative decomposition of benzene and its methyl derivatives catalyzed by copper and palladium ion-exchanged Y-type zeolite is reported by Becker et al. [14]. They have observed the presence of microcrystalline $\mathrm{CuO}$ phases in the catalyst by EXAFS experiments and the equilibrium between $\mathrm{Cu}(\mathrm{I})$ and $\mathrm{CuO}$ is probably the rate determining step for the oxidation reaction.

Velu et al. [15] have utilized MCM-41 mesoporous molecular sieves containing copper and zinc for the selective oxidation of alcohols to aldehydes. They have also observed the presence of finely dispersed $\mathrm{CuO}$ inside the channels of MCM-41 which produce overoxidation products, namely, $\mathrm{CO}_{2}$ and $\mathrm{H}_{2} \mathrm{O}$. Lin and Wang [16] have reported the oxidation of 2-chlorophenol catalyzed by CuO/ZSM-48 derived from the calcination of $\mathrm{Cu}^{2+}$-exchanged in zeolite at $500^{\circ} \mathrm{C}$. For the cation exchange, they have used $\mathrm{Cu}\left(\mathrm{OCOCH}_{3}\right)_{2}$ in aqueous solution. They have also reported that the oxidation efficiency of 2-chlorophenol in the supercritical water is efficiently enhanced by the presence of $\mathrm{CuO}$ in the zeolite. 


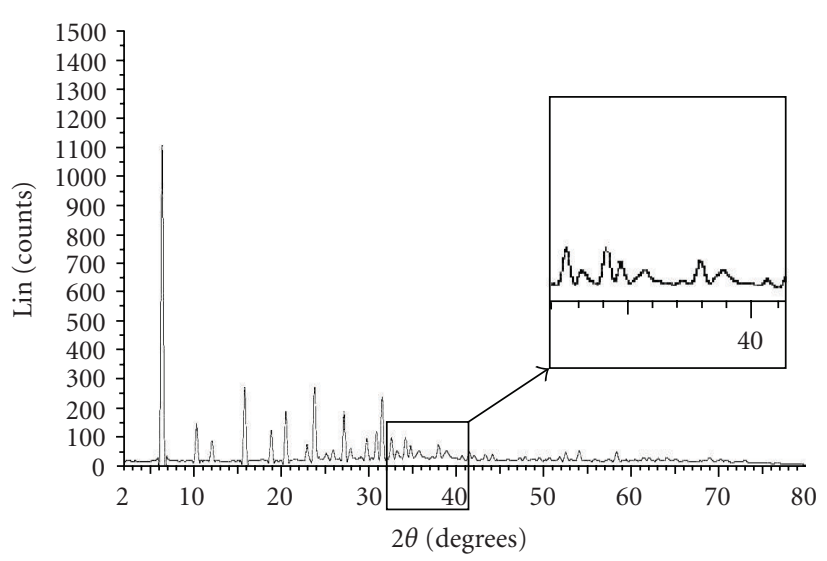

(a)

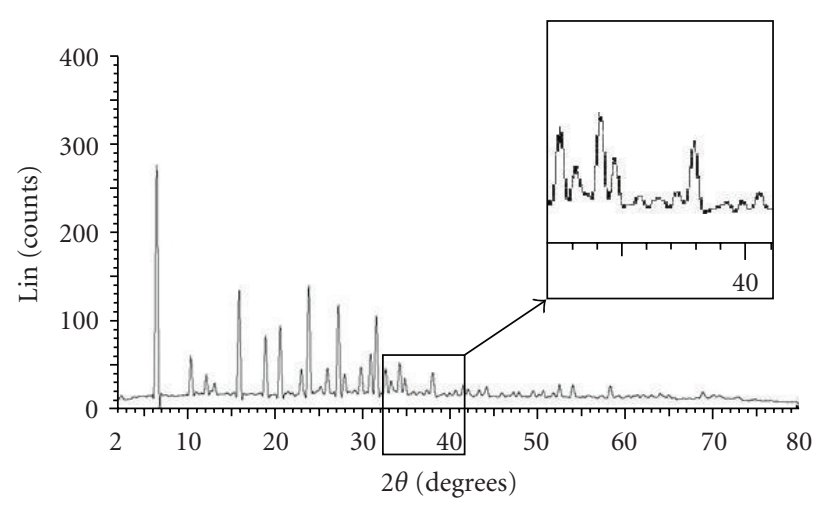

(b)

FIGURE 1: Powder XRD patterns of (a) $\mathrm{Cu}^{2+}$ exchange Y-zeolite, and (b) zeolite encapsulated nanocrystalline $\mathrm{CuO}$.

In earlier reports for preparation of $\mathrm{CuO}$ containing zeolites, calcination procedure is utilized (calcination of $\mathrm{Cu}^{2+}$-exchanged zeolite at $500^{\circ} \mathrm{C}$ ) and only microcrystalline $\mathrm{CuO}$ phases are observed. However, there are no reports for the syntheses of nanocrystalline $\mathrm{CuO}$ in the supercage of $\mathrm{Y}$ zeolite. The shape and size of the zeolite cavities, particularly the cages and polar active sites are expected to stabilize the $\mathrm{CuO}$ nanoparticles and thus prevent their aggregation. Hence, in the present study, it is proposed to synthesize nanocrystalline $\mathrm{CuO}$ encapsulated inside the supercages of Y-zeolite and to study its catalytic activity in the oxidation of alcohols.

\section{EXPERIMENTAL METHODS}

\subsection{Preparation of zeolite encapsulated nanocrystalline CuO}

Zeolite encapsulated nanocrystalline $\mathrm{CuO}$ was synthesized from $\mathrm{Cu}^{2+}$-exchanged Y-zeolite. About $2 \mathrm{~g}$ of $\mathrm{Cu}^{2+}$ exchanged Y-zeolite were taken in a round-bottomed flask containing $10 \mathrm{~mL}$ of deionized water and they were heated to $80^{\circ} \mathrm{C}$ in a water bath. To the hot mixture, $2 \mathrm{~mL}$ of $10 \%$ sodium hydroxide solution was added with constant stirring. First, the bluish green $\mathrm{Cu}^{2+}$ Y-zeolite becomes dark blue by the formation of $\mathrm{Cu}(\mathrm{OH})_{2}$, then it changed in situ into black colour by the formation of $\mathrm{CuO}$. The mixture was stirred at room temperature for 6 hours and then it was separated by centrifuging. It was washed thrice with water, centrifuged, and the precipitate was dried in an air oven at $100^{\circ} \mathrm{C}$.

\subsection{Oxidation of secondary alcohols}

Zeolite encapsulated nanocrystalline $\mathrm{CuO} 300 \mathrm{mg}$ was activated in a muffle furnace at $450^{\circ} \mathrm{C}$ for 6 hours. The hot zeolite was immediately transferred into $5 \mathrm{~mL}$ of $\mathrm{n}$-hexane to avoid absorption of water. Then, $100 \mathrm{mg}$ of benzhydrol were loaded into the zeolite by stirring it in a magnetic stirrer. After loading, $n$-hexane was evaporated with rotovapor and then it was dried. Alcohol-loaded zeolite was uniformly packed in a sample loading unit and it was fitted into the reactor. Oxygen was allowed to flow into the reactor with a rate of $1 \mathrm{~mL} / \mathrm{min}$. The temperature of the reactor was maintained at $200^{\circ} \mathrm{C}$. After 1 hour, the products condensed on the receiver and also on zeolite were extracted with dichloromethane and the mass balance was noted. Then, the reaction mixture was analyzed in GC, and the products were characterized in GCMS.

\section{RESULTS AND DISCUSSION}

\subsection{Characterization of zeolite encapsulated nanocrystalline CuO}

In this paper, zeolite encapsulated nanocrystalline $\mathrm{CuO}$ is synthesized by the addition of $\mathrm{NaOH}$ solution to a suspension of $\mathrm{Cu}^{2+}$-exchanged zeolites. Here, the procedure similar to that reported by Cao et al. [10] is adopted. They have used $\mathrm{CTAB}$ as capping agent which prevents the aggregation of nanoparticle. But in our study, the shape of the supercage and its polar active sites are likely to prevent the aggregation of nanocrystalline $\mathrm{CuO}$ and consequently no capping agent is used. Formation of $\mathrm{CuO}$ from $\mathrm{Cu}^{2+}$ is characterized by its powder XRD and its nano form is confirmed by HRTEM analysis. The prepared nanocrystalline $\mathrm{CuO}$ encapsulated $\mathrm{CuY}$ zeolite is characterized by AAS, powder XRD, SEM, and HRTEM analyses, and the observed results are given below.

AAS analysis of $\mathrm{CuO}$ encapsulated $\mathrm{CuY}$ zeolite shows $8.4 \mathrm{wt} \%$ of copper present in the zeolite. However, with this result alone, it is difficult to come to a conclusion about the percentage of $\mathrm{CuO}$ and $\mathrm{Cu}^{2+}$ (as a cation) presents inside the zeolite. Powder XRD pattern of $\mathrm{Cu}^{2+}$-exchanged and zeolite encapsulated nanocrystalline $\mathrm{CuO}$ is given in Figure 1. The presence of peaks corresponding to $\mathrm{CuO}$ (at $2 \theta=34$ and $2 \theta=38)^{16}$ confirms the presence $\mathrm{CuO}$ in the zeolite. Pure $\mathrm{Cu}^{2+}{ }_{-} \mathrm{Y}$ zeolite also has small peaks that corresponding to $\mathrm{CuO}$ and this may be due to the formation of trace amount of $\mathrm{CuO}$ by partial oxidation of $\mathrm{Cu}^{2+}$ to $\mathrm{CuO}$ during cation exchange and drying the cation-exchanged sample in an air oven. There have been no other changes in the other diffraction peaks of the zeolite and the crystallinity of the zeolite is maintained even after the base treatment of the zeolites. 


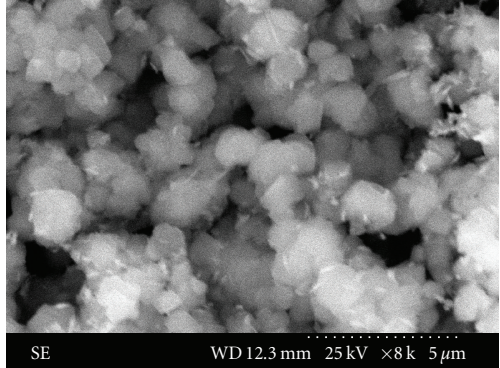

(a)

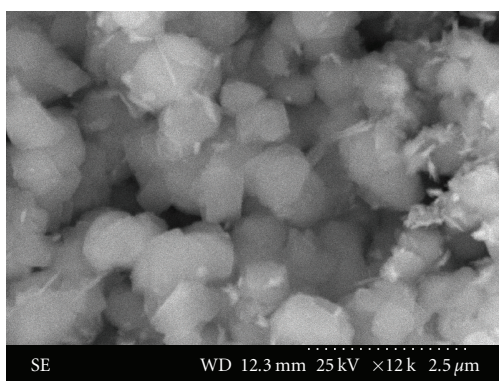

(c)

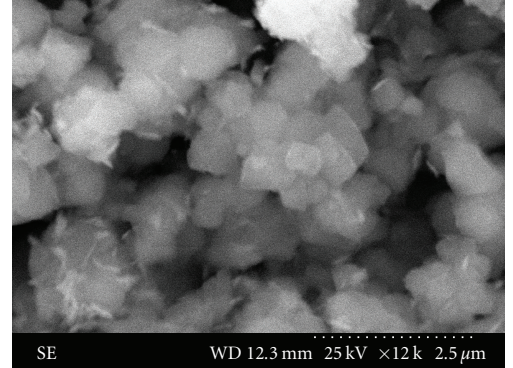

(b)

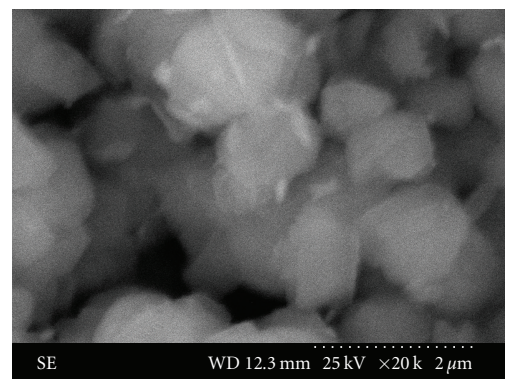

(d)

FIGURE 2: SEM images of zeolite encapsulated nanocrystalline $\mathrm{CuO}$ at different magnifications.

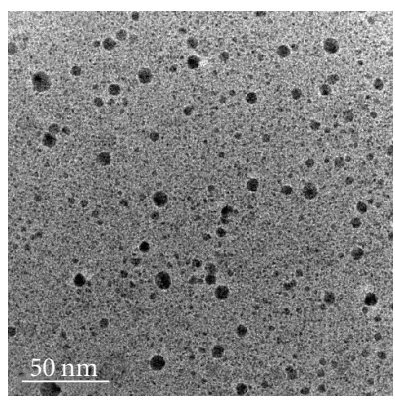

(a)

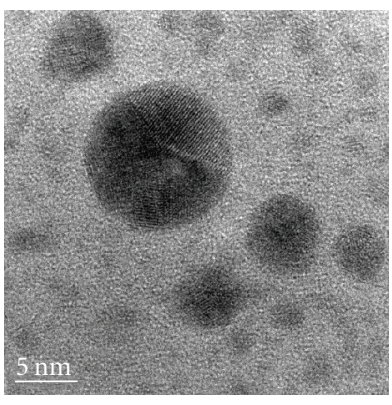

(b)

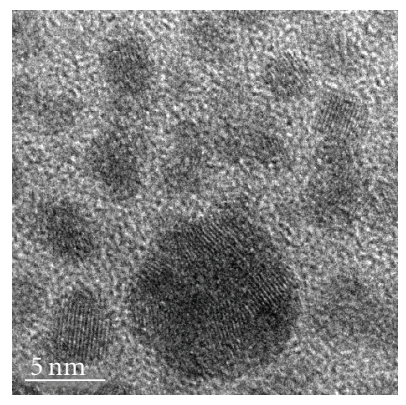

(c)

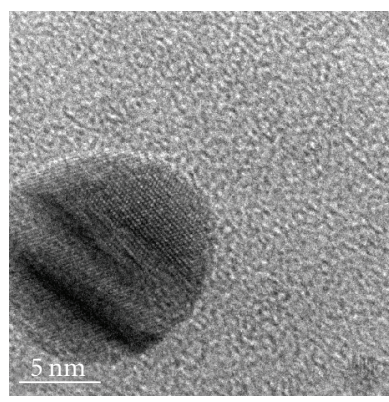

(d)

FIGURE 3: HRTEM images of zeolite encapsulated nanocrystalline $\mathrm{CuO}$ at different magnifications.

SEM analysis of zeolite encapsulated nanocrystalline $\mathrm{CuO}$ shows the surface morphology of the zeolite (Figure 2). Zeolite particles are found to be present as granules of particle size $\sim 500 \mathrm{~nm}$. HRTEM images of zeolite encapsulated nanocrystalline $\mathrm{CuO}$ at different magnifications are given in Figure 3. These figures clearly show that the $\mathrm{CuO}$ particles are in nanometer range $(<15 \mathrm{~nm})$ and most of the particles (which are less than $2 \mathrm{~nm}$ ) are embedded inside the zeolite materials (Figures 3(b) and 3(c)). These $\mathrm{CuO}$ nanoparticles are also spherical in shape. Few other particles in the range of $15 \mathrm{~nm}$ are also found and this is attributed to the passage of high energy beam during the HRTEM analysis and consequent cage-escape and aggregation of $\mathrm{CuO}$ nanoparticles.

HRTEM images reveal that nanocrystalline $\mathrm{CuO}$ particles are highly dispersed and no aggregation or cluster formation occurs. This may be due to the interaction between the zeolites active sites and the $\mathrm{CuO}$ surface, which have high surface energy due to its smaller size [17]. Further, the formation of the nanocrystalline $\mathrm{CuO}$ inside the supercages of Y-zeolite was confirmed by the BET pore-size and pore volume of the CuY-zeolite. The pore size and pore volume of $\mathrm{CuY}$-zeolite before and after nano $\mathrm{CuO}$ formation are $16.11 \AA, 0.3179 \mathrm{cc} / \mathrm{g}$ and $15.19 \AA, 0.2608 \mathrm{cc} / \mathrm{g}$, respectively. The decrease in the average pore diameter and the pore volume clearly indicates the formation of nanocrystalline $\mathrm{CuO}$ within the supercages of zeolite without damaging the zeolite crystal structure.

$\mathrm{CuO}$ has been widely used as a catalyst for the oxidation of alcohols and aromatic hydrocarbons [12-15]. Here, zeolite encapsulated nanocrystalline $\mathrm{CuO}$ is used for the oxidation of aromatic alcohols. Since $\mathrm{CuO}$ is mildly basic and zeolites are mildly acidic, this combination will provide an acid-base bifunctional catalyst. In addition, zeolite supercages will also 
TABLE 1: Zeolite encapsulated nanocrystalline $\mathrm{CuO}$ catalyzed oxidation of alcohols ${ }^{(\mathrm{a})}$.

\begin{tabular}{|c|c|c|c|c|c|c|c|c|}
\hline \multirow{2}{*}{ S. No } & \multirow{2}{*}{ Substrate } & \multirow{2}{*}{ Catalyst } & \multirow{2}{*}{$\%$ Conversion $^{(\mathrm{b})}$} & \multicolumn{5}{|c|}{$\%$ of products } \\
\hline & & & & 2 & 3 & 4 & 5 & $\mathrm{X}^{(\mathrm{c})}$ \\
\hline (1) & Benzoin & $\mathrm{CuOY}$ & 100 & 92.2 & - & - & - & 7.8 \\
\hline (2) & Benzhydrol & $\mathrm{CuOY}$ & 100 & 29.1 & 70.9 & - & - & - \\
\hline (3) & & $\mathrm{CuOY}^{(\mathrm{d})}$ & nil & - & - & - & - & - \\
\hline (4) & & $\mathrm{Cu}^{2+} \mathrm{Y}$ & 21.0 & 28.7 & 71.3 & - & - & - \\
\hline (5) & & $\mathrm{NaY}$ & 11.2 & - & 100 & - & - & - \\
\hline (6) & & $\mathrm{CuO}$ & 100 & 100 & - & - & - & - \\
\hline (7) & & Y-zeolite-CuO ${ }^{(e)}$ & 100 & 90.0 & 8.4 & - & - & 1.6 \\
\hline (8) & \multirow{2}{*}{ 1-Phenylethanol } & $\mathrm{CuOY}$ & 100 & - & - & 84.9 & - & 15.1 \\
\hline (9) & & $\mathrm{CuO}$ & 78.0 & 100 & - & - & - & - \\
\hline (10) & Hydrobenzoin & $\mathrm{CuOY}$ & 100 & - & - & - & 100 & - \\
\hline$(11)$ & Benzyl alcohol & $\mathrm{CuOY}$ & 13.7 & 100 & - & - & - & - \\
\hline
\end{tabular}

(a) Substrate loaded zeolite heated in solid phase reactor at $200^{\circ} \mathrm{C}$ for 1 hour under oxygen atmosphere.

(b) Analyzed in GC, error limit $\pm 3 \%$.

(c) Unidentified products.

(d) Reaction carried out at $100^{\circ} \mathrm{C}$.

(e) Physical mixture of Y-zeolite and $\mathrm{CuO}$.

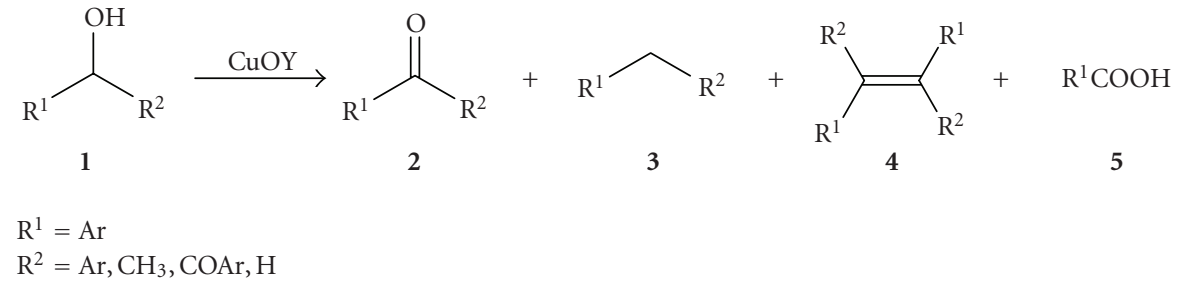

SCHEMe 1

provide closer proximity between substrates, adjacent acidic, and basic sites which is expected to increase the rate of the reaction. In general, catalytic activity of $\mathrm{CuO}$ is maximum at higher temperature and hence, we have developed a solid-phase reactor provided with constant flow of oxygen. The results obtained for the oxidation of various aromatic alcohols using zeolite encapsulated nanocrystalline $\mathrm{CuO}$ are given in Table 1 and Scheme 1 .

In the oxidation of benzoin with zeolite encapsulated nanocrystalline $\mathrm{CuO}$ in the solid phase reactor, the oxidation product, namely, benzil is formed in good yield. But with benzhydrol, benzophenone, and diphenylmethane, the oxidized as well as reduced products, respectively, are formed. However, at a lower temperature $\left(100^{\circ} \mathrm{C}\right)$, there is no reaction (Table 1 , entry 3 ). With only $\mathrm{Cu}^{2+}$-exchanged zeolite, the conversion is lower and a similar product ratio is observed. Hence, it is likely that at an elevated temperature, $\mathrm{Cu}^{2+}$ in oxygen atmosphere may have been oxidized to $\mathrm{CuO}$. Similarly, when studied in NaY zeolite also, the conversion is very low and only the reduced product is observed. In the presence of pure $\mathrm{CuO}$, only the oxidized product is formed exclusively.

When 1-phenylethanol is subjected to oxidation under the same conditions, the oxidative-coupled product an alkene (1,2-dimethylstilbene) is formed. Hydrobenzoin, an aromatic diol, undergoes overoxidation to produce benzoic acid. With an aromatic primary alcohol, namely benzyl alcohol, the conversion is very low (Table 1 , entry 10). It is likely that because of its lower boiling point, it may be vaporized before it reacts with the catalyst as it is found to be condensed on the receiver. Thus, this method is found to be efficient only for alcohols having higher boiling points.

\subsection{Mechanism for the oxidation of alcohols}

Nagase et al. [18] have studied the dynamic oxidation states of copper in the course of carbon monoxide oxidation over powdered $\mathrm{CuO}$ and $\mathrm{Cu}_{2} \mathrm{O}$ in a gas mixture of $5 \% \mathrm{CO} / \mathrm{He}$ and air $\left(\mathrm{O}_{2}\right)$ by means of an appropriate combination of evolved gas analysis, thermogravimetry, XRD, and FT-IR in the temperature range of room temperature to $350^{\circ} \mathrm{C}$. They have observed the reduction of $\mathrm{CuO}$ to $\mathrm{Cu}$ and the stepwise oxidation of $\mathrm{Cu} \rightarrow \mathrm{Cu}_{2} \mathrm{O} \rightarrow \mathrm{CuO}$ from the XRD spectra of the products after each process. Hence, the oxidation state of copper changes thermodynamically between $\mathrm{CuO}, \mathrm{Cu}_{2} \mathrm{O}$, and $\mathrm{Cu}$ as a function of temperature and oxygen atmosphere. This redox behavior and the difference in oxygen defects, oxygen holes, and oxygen adsorption species in these oxidation states are thought to be the reason for the high activity or selectivity of the copper catalyst. 


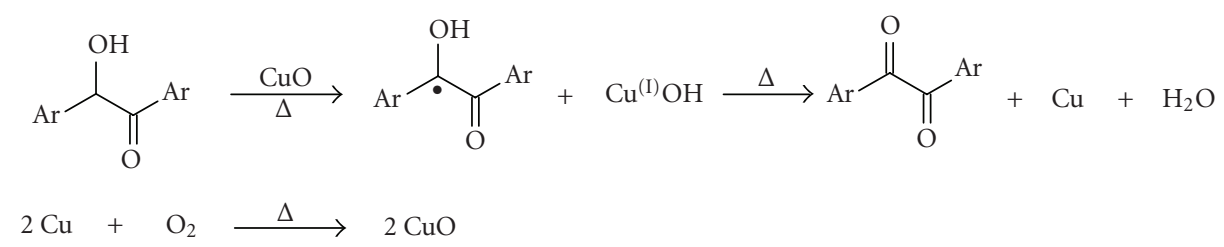

Scheme 2: Proposed mechanism for the oxidation of benzoin catalyzed by zeolite encapsulated nanocrystalline CuO.

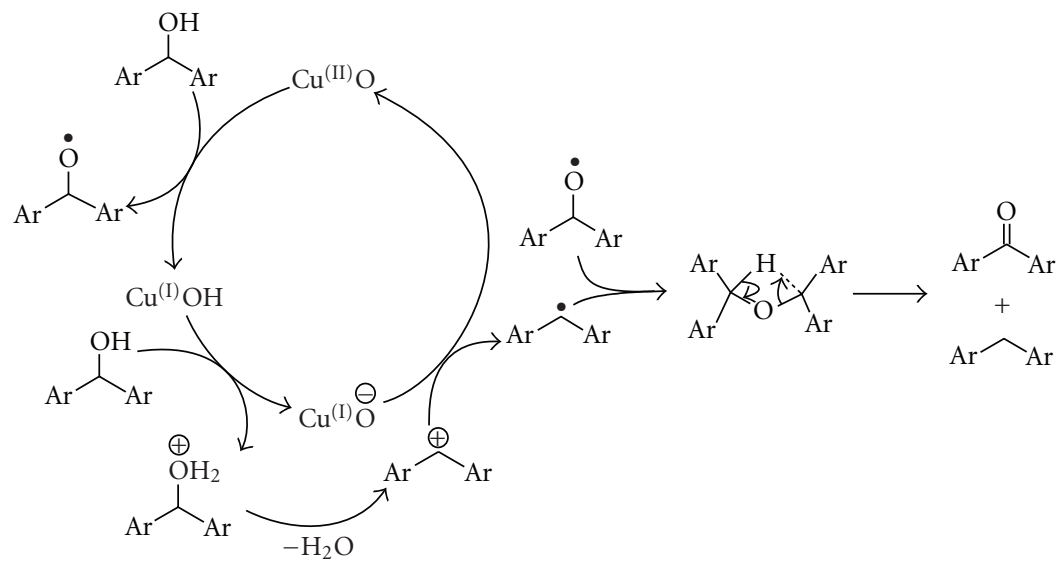

Scheme 3: Proposed mechanism for the oxidation/reduction of benzhydrol catalyzed by zeolite encapsulated nanocrystalline CuO.

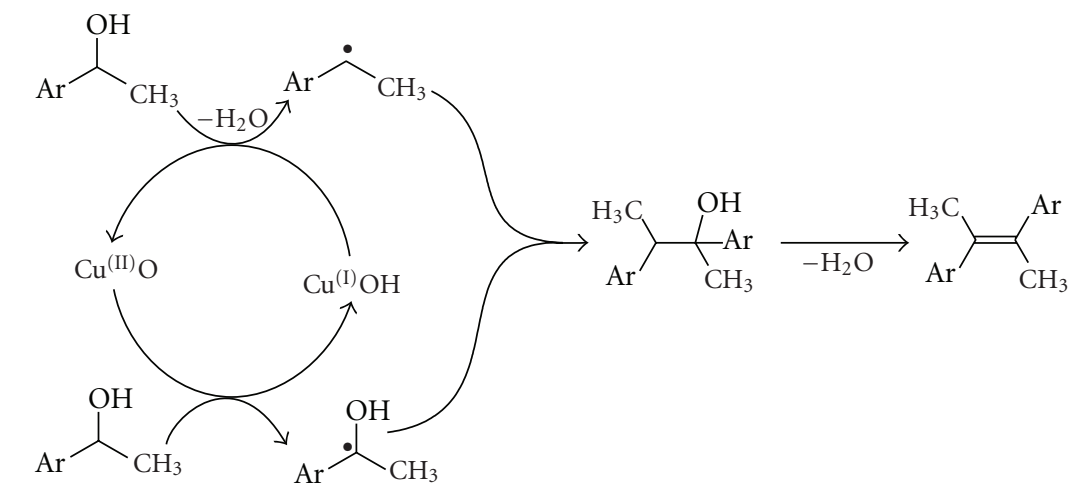

Scheme 4: Proposed mechanism for the coupling of 1-phenylethanol catalyzed by zeolite encapsulated nanocrystalline CuO.

Earlier Sheikh and Eadon [19] have reported the vaporphase oxidation of alcohols to aldehydes and ketones by cupric oxide as a catalyst. They have proposed a homolytic cleavage of $\mathrm{C}-\mathrm{H}$ and $\mathrm{O}-\mathrm{H}$ bonds for the oxidation of alcohols catalyzed by $\mathrm{CuO}$. A similar mechanism may also be proposed in our case too, when benzoin is oxidized to benzil (Scheme 2). In this process, $\mathrm{CuO}$ is proposed to be reduced to $\mathrm{Cu}$, and this $\mathrm{Cu}$ may undergo aerial oxidation to regenerate $\mathrm{CuO}$.

Benzhydrol behaves differently with $\mathrm{CuO}$ encapsulated $\mathrm{CuY}$ zeolite. With pure $\mathrm{CuO}$, benzhydrol gives benzophenone as the sole product. However, with $\mathrm{CuO}$ encapsulated $\mathrm{CuY}$ zeolite, the oxidized product benzophenone as well as the reduced product, diphenylmethane, is obtained. It is rel- evant to note that under supercritical water, diarylmethanols and its derivatives are transformed into diarylmethanes and diarylketones [20]. This disproportionation is considered to proceed via a hydrogen transfer from bis(diarylmethyl)ether intermediate. The same group has also reported the formation of diarylalkanes from diarylketones under supercritical 2-propanol [21]. Earlier, Gribble et al. [22] have reported the reduction of diarylketone with $\mathrm{NaBH}_{4}$ in $\mathrm{CF}_{3} \mathrm{CO}_{2} \mathrm{H}$ to yield diarylmethane.

Zeolite plays a vital role in the oxidation/reduction of benzhydrol. In the oxidation of benzhydrol with pure $\mathrm{CuO}$, benzophenone is formed as the sole product. However, in presence of $\mathrm{CuY}$ zeolite, diphenylmethane, the reduced product is also formed. To account for this, it is proposed 
that zeolite supercage provides closer proximity between the reactants resulting in the formation of the intermediate bis(diarylmethyl) ether. This ether undergoes disproportionation to form alcohol and ketone (see Supplementary Figure available online at doi:10.1155/2008/257691). A plausible mechanism is proposed for the oxidation/reduction of benzhydrol catalyzed by $\mathrm{CuO}$ encapsulated $\mathrm{CuY}$ zeolite (Scheme 3). To confirm this, a control experiment was also performed with a physical mixture of Y-zeolite and $\mathrm{CuO}$. Here, a vastly different products distribution was obtained with only $8.4 \%$ of reduced product and the remaining being the oxidized product. This clearly indicates that the acidbase bifunctionality is due to encapsulation of $\mathrm{CuO}$ inside the zeolite framework.

In the oxidation of benzhydrol, hydrogen transfer to $\mathrm{CuO}$ takes place involving homolytic cleavage of hydroxyl group. This reduces $\mathrm{Cu}^{(\mathrm{II})}$ to $\mathrm{Cu}^{(\mathrm{I})}$ which can readily eliminate $\mathrm{H}^{+}$. This $\mathrm{H}^{+}$will protonate benzhydrol which followed by dehydration forms the corresponding cation. This cation may be reduced by the $\mathrm{Cu}(\mathrm{I})$ to diphenylmethyl radical. Combination of this with the initially formed diarylmethyleneoxy radical leads to the formation of bis(diarylmethyl) ether intermediate. Disproportionation of this intermediate proceeds, through intramolecular hydrogen transfer to give diarylmethane and diarylketone. The redox behavior of $\mathrm{Cu}$ provides a useful regeneration of the catalyst.

In the case of 1-phenylethanol, 1,2-dimethylstilbene is formed as the major product. To account for this, the following mechanism is proposed (Scheme 4). Here, 2,3diphenyl-2-butanol intermediate is proposed which may undergo dehydration to form the alkene.

\section{CONCLUSIONS}

Zeolite encapsulated nanocrystalline $\mathrm{CuO}$ (particle size less than $15 \mathrm{~nm}$ ) is synthesized successfully and is characterized by powder XRD, SEM, and HRTEM analyses. The nanoparticles are highly dispersed. This $\mathrm{CuOY}$ is used as catalysts in the oxidation of aromatic alcohols. Secondary alcohols undergo oxidation to a greater extent and primary alcohols react very slowly. With benzhydrol, disproportionation takes place leading to both oxidation as well as reduction products (benzophenone and diphenylmethane, resp.). CuY zeolite acts as an efficient support for nano $\mathrm{CuO}$, by stabilizing it and preventing its aggregation. The process is also significant in that it is a new method for the synthesis of diphenylmethane, a useful material in spice production and also an important intermediate in drug and organic synthesis [23]. Plausible mechanisms for the formation of the various products are also given.

\section{ACKNOWLEDGMENTS}

Kasi Pitchumani thanks the University Grants Commission (for sanctioning UPE program to Madurai Kamaraj University) and the Department of Science and Technology, New Delhi, India, for financial assistance.

\section{REFERENCES}

[1] A. T. Bell, "The impact of nanoscience on heterogeneous catalysis," Science, vol. 299, no. 5613, pp. 1688-1691, 2003.

[2] G. C. Bond and D. T. Thompson, "Catalysis by gold," Catalysis Reviews Science and Engineering, vol. 41, no. 3-4, pp. 319-388, 1999.

[3] P. K. Stoimenov, V. Zaikovski, and K. J. Klabunde, "Novel halogen and interhalogen adducts of nanoscale magnesium oxide," Journal of the American Chemical Society, vol. 125, no. 42, pp. 12907-12913, 2003.

[4] R. Narayanan and M. A. El-Sayed, "Shape-dependent catalytic activity of platinum nanoparticles in colloidal solution," Nano Letters, vol. 4, no. 7, pp. 1343-1348, 2004.

[5] B. M. Choudary, V. S. Jaya, B. R. Reddy, M. L. Kantam, M. M. Rao, and S. S. Madhavendra, "Synthesis, characterization, ion exchange, and catalytic properties of nanobinary and ternary metal oxy/hydroxides," Chemistry of Materials, vol. 17, no. 10, pp. 2740-2743, 2005.

[6] L. Rout, S. Jammi, and T. Punniyamurthy, "Novel CuO nanoparticle catalyzed C-N cross coupling of amines with iodobenzene," Organic Letters, vol. 9, no. 17, pp. 3397-3399, 2007.

[7] C. L. Carnes, J. Stipp, K. J. Klabunde, and J. Bonevich, "Synthesis, characterization, and adsorption studies of nanocrystalline copper oxide and nickel oxide," Langmuir, vol. 18, no. 4, pp. 1352-1359, 2002.

[8] K. Zhou, R. Wang, B. Xu, and Y. Li, "Synthesis, characterization and catalytic properties of $\mathrm{CuO}$ nanocrystals with various shapes," Nanotechnology, vol. 17, no. 15, pp. 3939-3943, 2006.

[9] B. Liu and H. C. Zeng, "Mesoscale organization of $\mathrm{CuO}$ nanoribbons: formation of "dandelions"', Journal of the American Chemical Society, vol. 126, no. 26, pp. 8124-8125, 2004.

[10] M. Cao, C. Hu, Y. Wang, Y. Guo, C. Guo, and E. Wang, "A controllable synthetic route to $\mathrm{Cu}, \mathrm{Cu}_{2} \mathrm{O}$, and $\mathrm{CuO}$ nanotubes and nanorods," Chemical Communications, vol. 9, no. 15, pp. 1884-1885, 2003.

[11] J. Bandara, C. P. K. Udawatta, and C. S. K. Rajapakse, "Highly stable $\mathrm{CuO}$ incorporated $\mathrm{TiO}_{2}$ catalyst for photocatalytic hydrogen production from $\mathrm{H}_{2} \mathrm{O}$," Photochemical \& Photobiological Sciences, vol. 4, no. 11, pp. 857-861, 2005.

[12] T. Miyahara, H. Kanzaki, R. Hamada, S. Kuroiwa, S. Nishiyama, and S. Tsuruya, "Liquid-phase oxidation of benzene to phenol by $\mathrm{CuO}-\mathrm{Al}_{2} \mathrm{O}_{3}$ catalysts prepared by coprecipitation method," Journal of Molecular Catalysis A, vol. 176, no. 1-2, pp. 141-150, 2001.

[13] M. Zimowska, A. Michalik-Zym, R. Janik, et al., "Catalytic combustion of toluene over mixed Cu-Mn oxides," Catalysis Today, vol. 119, no. 1-4, pp. 321-326, 2007.

[14] L. Becker and H. Förster, "Oxidative decomposition of benzene and its methyl derivatives catalyzed by copper and palladium ion-exchanged Y-type zeolites," Applied Catalysis B, vol. 17, no. 1-2, pp. 43-49, 1998.

[15] S. Velu, L. Wang, M. Okazaki, K. Suzuki, and S. Tomura, "Characterization of MCM-41 mesoporous molecular sieves containing copper and zinc and their catalytic performance in the selective oxidation of alcohols to aldehydes," Microporous and Mesoporous Materials, vol. 54, no. 1-2, pp. 113-126, 2002.

[16] K.-S. Lin and H. P. Wang, "Shape selectivity of trace byproducts for supercritical water oxidation of 2-chlorophenol effected by CuO/ZSM-48," Applied Catalysis B, vol. 22, no. 4, pp. 261-267, 1999.

[17] L. Sun, Z. Zhang, Z. Wang, Z. Wu, and H. Dang, "Synthesis and characterization of $\mathrm{CuO}$ nanoparticles from liquid 
ammonia," Materials Research Bulletin, vol. 40, no. 6, pp. 1024-1027, 2005.

[18] K. Nagase, Y. Zheng, Y. Kodama, and J. Kakuta, "Dynamic study of the oxidation state of copper in the course of carbon monoxide oxidation over powdered $\mathrm{CuO}$ and $\mathrm{Cu}_{2} \mathrm{O}$," Journal of Catalysis, vol. 187, no. 1, pp. 123-130, 1999.

[19] M. Y. Sheikh and G. Eadon, "The vapor phase oxidation of alcohols by cupric oxide. A convenient preparation of aldehydes and ketones," Tetrahedron Letters, vol. 13, no. 4, pp. 257-260, 1972.

[20] B. Hatano, J.-I. Kadokawa, and H. Tagaya, "Disproportionation of diarylmethanol derivatives by using supercritical water," Tetrahedron Letters, vol. 43, no. 33, pp. 5859-5861, 2002.

[21] B. Hatano and H. Tagaya, "Novel direct reduction of diaryl ketones to diarylmethanes using supercritical 2-propanol," Tetrahedron Letters, vol. 44, no. 33, pp. 6331-6333, 2003.

[22] G. W. Gribble, W. J. Kelly, and S. E. Emery, "Reactions of sodium borohydride in acidic media; VII. Reduction of diaryl ketones in trifluoroacetic acid," Synthesis, no. 10, pp. 763-765, 1978.

[23] Z. Hou and T. Okuhara, "Catalytic synthesis of diphenylmethane from benzene and formalin with water-tolerant solid acids," Applied Catalysis A, vol. 216, no. 1-2, pp. 147-155, 2001. 

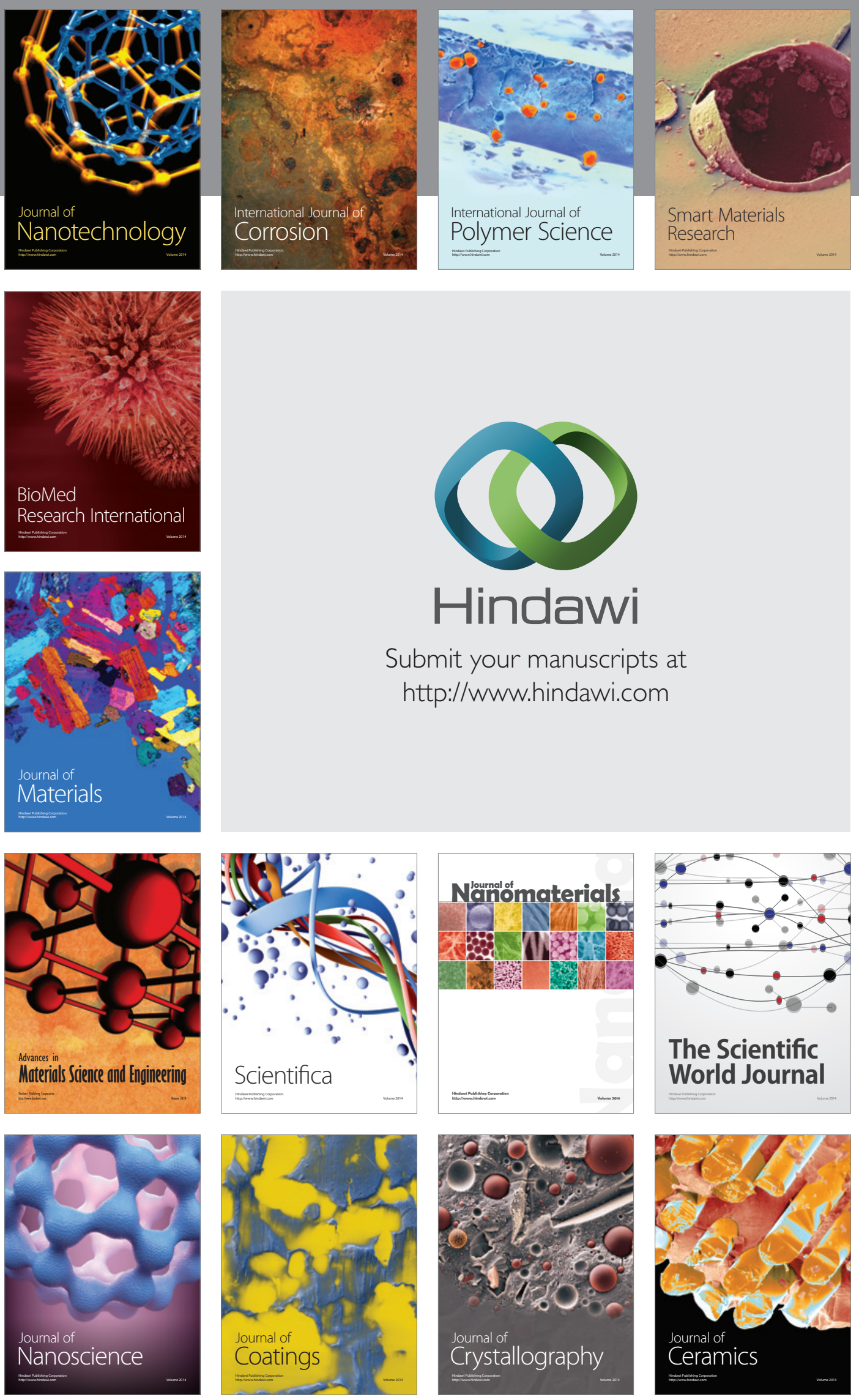

The Scientific World Journal

Submit your manuscripts at

http://www.hindawi.com

\section{World Journal}

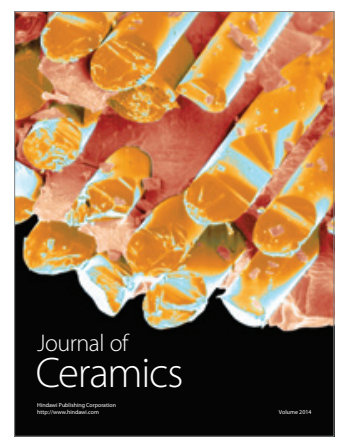

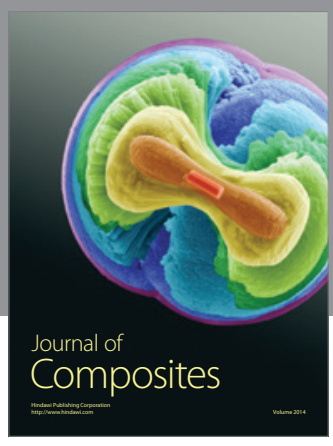
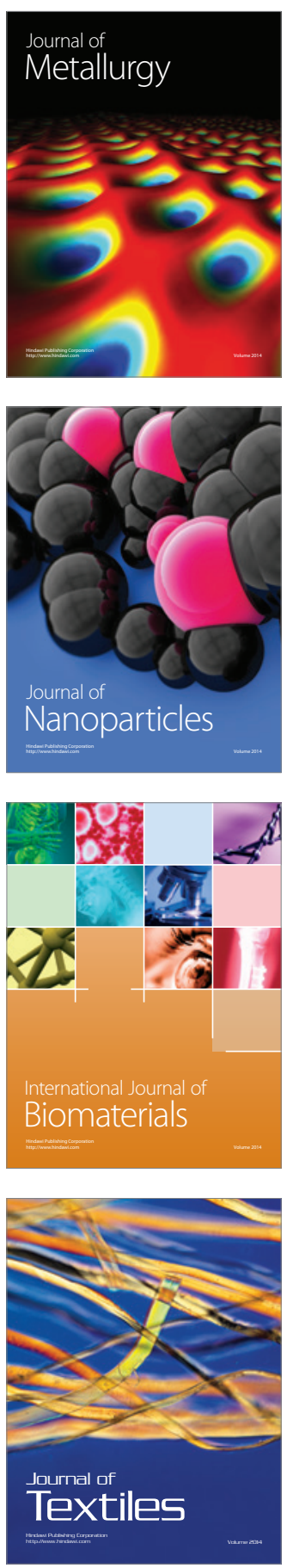